Comparative Philosophy Volume 5, No. 2 (2014): 35-44

Open Access / ISSN 2151-6014

www.comparativephilosophy.org

\title{
ECOLOGICAL TENSION: BETWEEN MINIMUM AND MAXIMUM CHANGES
}

\author{
CHANGFU XU
}

\begin{abstract}
This article elaborates the conditions as well as four potential modes of the ecological problem: (1) The mode of the absolute minimization of the ecological problem: minimum population plus minimum Gross Domestic Product (GDP), which is characterized by the quantity of destruction being less than the quantity of natural rehabilitation of an ecosystem. This mode is the poorest mode with minimum change. (2) The mode of the relative minimization of the ecological problem: minimum population plus maximization of GDP, which is characterized by the quantity of destruction being less than the quantity of both natural rehabilitation and human rehabilitation of an ecosystem. This mode is the best mode with minimum change. (3) The mode of the relative maximization of the ecological problem: maximization of population plus minimum GDP, which is characterized by the quantity of destruction to the ecosystem not being offset by the quantity of human rehabilitation. An example of this mode is an underdeveloped district with vast population and limited farmland. (4) The mode of the absolute maximization of the ecological problem: maximization of population plus maximization of GDP. This is characterized by the continuous increase of the quantity of destruction beyond the quantity of both natural rehabilitation and human rehabilitation of the ecosystem. Its final outcome is the collapse of the ecosystem and a catastrophe to human beings.
\end{abstract}

Keywords: ecosystem; population; GDP; destruction; rehabilitation

\section{THREE CONDITIONS FOR OCCURRENCE OF ECOLOGICAL PROBLEMS:}

Ecological problems do not occur in a vacuum. There are no ecological problems in the world without an ecosphere. For example, no ecological problems occur on the moon because there is no life. And there were no ecological problems on the earth before the existence of life either. There are no ecological problems in the world with an ecosphere but without human activity. Before the existence of human beings, there were no ecological problems on the earth, even though other creatures had already

XU, CHANGFU: Professor, Institute of Marxist Philosophy and Chinese Modernization \& Department of Philosophy, Sun Yat-sen University, China. Email: xuchf@mail.sysu.edu.cn 
been flourishing for a long time.

Without human consciousness of ecology, there are potential ecological problems but no actual ecological problems in the world. Ancient Loulan City (Loulan-gucheng 楼兰古城), located in Xinjiang (新疆) province, once flourished but later became deserted due to exploitation of nature. It is true that Loulan City encountered ecological problems when seen from today's perspective. However, because the residents of Loulan City lacked the consciousness of ecology, we would regard them as potential ecological problems rather than actual ones.

There are actual ecological activities only in the world with an ecosphere, human activities and human consciousness. Ecological problems are problems peculiar to today's human beings.

\section{THE ESSENCE OF ECOLOGICAL PROBLEMS}

The essence of ecological problems is due to the fact that the destruction of ecosystems as a result of human activity harms human beings themselves. Ecological problems are defined as follows: (1) Destructive changes happen within an ecosystem; (2) Such changes have disadvantageous impacts on human beings; (3) Such changes are caused by the activities of human beings themselves. The typical ecological problems come from the industrial activities of human beings in the modern age.

Human beings exist by means of changing the world. By contrast, animals live in a way that complies with the order of nature. In the grasslands of Africa, the desertification caused by herbivorous animals has a negative impact on the subsistence of these animals in reverse. It seems to be an ecological problem but actually is not, because the ecological destruction caused by animals will be adjusted by natural causation rather than the animals themselves. Whether the process of desertification ends in complete desertification or automatic rehabilitation following the starvation of some herbivorous animals submits to laws of nature.

The means which human beings used to change the world have four dimensions: (1) needs and resources, (2) knowing and doing, (3) input and output, and (4) income and destruction. These four dimensions display the multiple two-sided features of human beings as both a part of nature and agents able to have an impact upon it.

Human needs are infinite, while utilizable resources are finite. Such a contradiction cannot be solved. Human beings can neither fix their needs once and for all on a certain level, nor find some unexhausted resource. They have to move between the two strategies.

Human beings have to apprehend the relation between needs and resources through knowledge, and have to obtain the resources to meet their needs through action. Action implies change to the world. The capacity to know and do enables human beings to get involved with the causal relation between needs and resources, and to achieve their goal of utilizing the resources to meet their needs.

Human beings can produce more resources as output only by means of resources in hand as input. The resource inputs are the costs, and the resource outputs deducting the costs is income, while the deficit is negative income. The causality and exchange 
between resources is obedient to laws of nature, e.g., the conservation of energy. As human beings are economic animals pursuing minimization of cost and maximization of income, the resources would be accumulatively transferred from nature to human beings.

Whether the income is positive or negative, any change is certain to cause corresponding damage in addition to input costs. The exploitation of natural resources by human beings has two costs: the first one is the economic cost; the second one is the ecological cost, i.e., ecological destruction. While the economic cost can be measured by an accounting list, the ecological destruction goes beyond the scope of accounting calculations.

When John Rawls talks about public harms such as environmental pollution, he also mentions a similar difference: "These costs are not normally reckoned with by the market, sot that the commodities produced are sold at much less than their marginal social costs. There is a divergence between private and social accounting that the market fails to register."1

Income can be accumulated, and damage can also be accumulated. The former can be carried out only under human control through knowing and doing, while the latter often eludes human control. Humans intend for an accumulation of income, and this is achieved by the economy or the whole social system; while the accumulation of destruction is unintended, and functions within an ecosystem or the whole natural system spontaneously.

It is through so-called modernization that humankind created a comprehensive objectified relationship with nature through scientific knowledge, technology and engineering. Modernization allows for human income to accumulate systematically, but at the same time, accumulates destruction in the ecological system. In the premodern age, the accumulation of income was achieved by individuals, and the impact of accumulation of destruction was communal. Both kinds of accumulations are discontinuous. But in the modern age, the accumulation of income is achieved by a given society while the accumulation of destruction becomes overall. Both kinds are continuative. Today, the accumulation of income and destruction are both global and irreversible.

An ecosystem is a system that runs spontaneously. The widespread accumulation of damage has resulted in notable demolition and rupture of ecological systems, which tampers with human ordinary life and even existence. This is a problem most people have become aware of. The ecological problem is a typical problem of globalization. In other words, only on a global stage can it be such a highlighted problem.

\section{TWO CONTRIBUTING FACTORS TO ECOLOGICAL PROBLEMS: POPULATION AND GDP}

The human population is a quantity of intelligent life that belongs to the ecological

\footnotetext{
${ }^{1}$ Rawls (1971, 268).

${ }^{2}$ See Fairbank $(1978,108-9)$.

${ }^{3}$ See Rawls $(1971,302)$.
} 
system. Gross Domestic Product (GDP) is a quantity of the natural resources extracted by human beings. The latter is the biggest factor produced by human action having significant impact on ecological system.

GDP is the modern symbol of income, which also implies an inevitable quantity of destruction. GDP means an economy's income with deduction of costs. Consumption of resources not only takes the form of economic costs, but also that of ecological destruction by releasing the waste into the ecological system.

Since an ecosystem has a function of natural rehabilitation, human beings may return part of GDP for the rehabilitation of an ecosystem according to their knowledge of ecological principles. This is the human rehabilitation of an ecosystem. An ecosystem can be rehabilitated in certain conditions. Such conditions can be natural or created by humans, but man-made conditions are composed of natural elements too.

The severity of ecological problems is in direct proportion to GDP and in inverse proportion to the proportion of GDP allocated for human rehabilitation of an ecosystem. Given that the GDP maintains a human individual's basic subsistence to a certain amount, the higher the population, the more the GDP is required; thus, the more resources are consumed, the more an ecosystem is destroyed. Similarly, if the GDP per capita surpasses the amount needed for basic subsistence, resources are consumed in proportion to this amount, and thus more of the ecosystem is destroyed. Part of the GDP can be used to rehabilitate the ecological system. The more the proportion of GDP is used for rehabilitation, the more the ecosystem is rehabilitated. However, this proportion cannot be raised indefinitely or it will clash with the original purpose of GDP.

The severity of ecological problems can be conceptualized through multiplying population by the quantity of destruction of GDP and then subtracting the quantity of natural rehabilitation and the quantity of human rehabilitation of an ecosystem. This is a basic formula for evaluating ecological problems. And the key to addressing ecological problems is to keep the balance between the quantity of destruction and the quantity of rehabilitation. This is the basic principle for dealing with ecological problems.

\section{FOUR MODES OF ECOLOGICAL PROBLEMS}

By combining and quantifying the two significant influential factors discussed in part 3 , we have four modes of ecological problems.

The first mode is that of the absolute minimization of the ecological problem: minimum population plus minimum GDP. It is characterized by the quantity of destruction being less than the quantity of natural rehabilitation of the ecosystem. An example is the aboriginal way of human life. This mode can be called the poorest mode with minimum change. This mode is the best for an ecosystem but the worst for human beings. However, it has huge ecological benefits.

The second mode is that of the relative minimization of the ecological problem: minimum population plus maximization of GDP. It is characterized by the quantity of 
destruction being less than the quantity of both natural rehabilitation and human rehabilitation of an ecosystem. We find this in sparsely inhabited developed countries. This mode can be called the best mode with minimum change. This mode is the best for both ecosystems and human beings. It represents the unity of human beings and ecosystems. Nevertheless, in the modern world, this unity is only the privilege of certain nations and does not belong to all human beings. Moreover, it presupposes that those nations use the ecological benefits in advance of others, and transfer ecological problems to other nations to some extent.

The third mode is that of the relative maximization of the ecological problem: maximization of population plus minimum GDP. It is characterized by the quantity of destruction being more than the quantity of natural rehabilitation of an ecosystem, and not being offset by the quantity of human rehabilitation, for example, in underdeveloped districts with vast populations and limited farmland. Before their economic take-off, China and India were taken as typical examples. The majority of population in these countries lived an extremely poor life and their ecological systems were substantially destroyed.

The fourth mode is that of the absolute maximization of the ecological problem: maximization of population plus maximization of GDP. It is characterized by the continuous increase of the quantity of destruction beyond the quantity of both natural rehabilitation and human rehabilitation of the ecosystem. Its final outcome is the collapse of the ecosystem and a human catastrophe.

Both China and India today are tending towards this mode. It has become too heavy a burden for the ecological system in those countries to maintain their people's basic subsistence with such a huge population. Their situation will become worse if those countries keep focusing on ever-increasing GDP and dreaming of surpassing the developed countries in the amount of GDP per capita. But the problem remains: if the GDP stops growing, how can the Chinese and Indian people be freed from poverty and live as well as the people in developed countries? This mode is the mode to which all human beings are headed. In fact, in a world where the population has surpassed seven billion, the average amount of GDP per capita of about 40,000 US dollars in developed countries has become the goal of people all over the world. As the world population and GDP per capita keep growing, human beings can foresee the ecological future by judging the multiplier effect of these two indices.

Still, there is a non-typical mode that is the artificial mode of an ecological system. It is characterized by constructing regional ecosystems through intensive investment. An example is Dubai. The artificial mode of its ecosystem is highly fragile. The GDP used to create and maintain this artificial system is at the expense of ecological destruction in other regions.

To sum up, all instances of ecological problems may be described with some qualification as one of these modes. The main point of this analytical framework is to reveal the most objective aspects of the ecological problems.

\section{TRANSFERABILITIES OF ECOLOGICAL PROBLEMS ACCORDING TO EGOIST PRINCIPLES}


The ecological system is not homogeneous and the distribution of ecological problems is unbalanced. Human nature is selfish. Ecological problems are transferable in different spheres and to different degrees, and they are transferred according to egoistic principles.

At first, the problem in an ecological unit or the smallest region can be transferred inter-individually. Ecological problems are transferred from powerful individuals to weak individuals. For example, the interdependence of the rich and the poor affects both GDP and the ecological problems in a region, but the rich can dwell in rich districts to enjoy the benefit of the maximization of GDP, while the poor have to dwell in slums and bear alone the effects of ecological problems. In China, there is a strong contrast between upscale residential gardens with high green coverage rate, and shanty towns at urban fringes and "cancer villages" in the outskirts of cities.

Then the problem of microcosmic ecosystems can be transferred inter-regionally. Ecological problems are transferred from powerful regions to weak regions so as to maximize the GDP and minimize the destruction of ecology in powerful regions. For example, in China, the coastal developed regions transfer their heavily polluting industries to the middle and western regions. For example, the high energyconsuming and heavily polluting enterprises in the Pearl River Delta in Guangdong province are gradually moving to the inner region of this province or to other inner provinces in China.

Furthermore, middle range ecological problems can be transferred internationally. Ecological problems are transferred from powerful countries to weak countries so as to maximize the GDP and minimize the destruction of ecosystems in powerful countries. For example, developed countries have been transferring their polluting industries to developing countries. For example, while China has attracted the most amount of foreign investments in the world, it has also suffered from the most amount of internationally transferred pollution in the world. The distinctive characteristics of the mode of China's development are to utilize foreign investment, import resources, export products, earn a narrow margin of profit and pollute its own environment.

The transfer, however, has its ultimate limit that macroscopic ecological problems cannot be transferred, so they must be faced by all human beings.

When there is no place to which the high energy-consuming and heavily polluting enterprises can be moved, the ecological problem will reach the saturation point on a global scale. In that case, the way of dealing with the ecological problem according to egoistic principles will come to an end.

\section{THE ROOT OF THE ECOLOGICAL PROBLEM IN CHINA: THE MAXIMIZATION OF CHANGE}

China has the largest population and the second highest amount of GDP in the world. The situation of the ecological problem in China before the reform and opening up policy is close to the mode of relative maximization. Before 1978, the GDP per capita 
of China was very low. Most people were struggling for their survival. The population is the basic influential factor in ecological problems.

The maximization of population is the most important factor of the ecological problem in China. The Chinese population was around 150 million in the late seventeenth century and reached 430 million in the mid-nineteenth century. ${ }^{2}$ Now the population of China has reached almost 1.4 billion. Any understanding of Chinese ecological problems must take this figure into account.

The idea of fighting against nature held by Chinese Marxists gave rise to many ecological disasters. From 1949 to 1978 , most of the Chinese people believed in Marxism. They took a radical atheist attitude toward nature, discarded traditional ecological consciousness of being in awe of heaven and earth, fought against nature and exploited natural resources in a crude way. Of course, they not only destroyed the ecosystem on a large scale, but also lost the income they should have had, i.e., the deserved potential rise of GDP.

Since the reform and opening up policy, the situation of the ecological problem in China has greatly deteriorated. Since 1978, the Chinese people have found a way to consistently raise GDP by introducing the market economy and joining the huge global market system conducted by western countries. Thus, GDP became the second biggest factor affecting the Chinese ecological system. The policy of family planning turns the impact of population on the ecosystem into a constant quantity, while the impact of GDP becomes the biggest variable quantity.

The maximization of population tends to aim at the maximization of GDP, while bearing the cost of ecological problems transferred from developed countries. Over the last 30 years, the GDP of China has grown at such a high speed that it has doubled its amount every ten years. Thus, it is the first time that this old civilization is expected to break from its historical cyclical chaos of widespread poverty to revolution, but the cost is the all-sided destruction of the ecological system.

The future of the ecological problem in China is very worrisome. It will influence the macroscopic ecosystem of the globe. As the developed countries still try to expand their GDP, China cannot slow down its pace for pursuing GDP. However, China's huge amount of GDP and its high growth rate will inevitably have a negative impact on the ecosystem of China, the eastern Asian region and even the world as a whole.

The ecosystem in China underwent a historical change from minimization of change to maximization of change. During most of the over 5,000 years' history of its civilization, China's ecological change has been minimized, but in less than two centuries under the impact of western civilization, China's ecological change was gradually maximized.

An example of minimization of change is the Dujiangyan (都江堰) irrigation system that has functioned for 22 centuries. The Dujiangyan irrigation system has very little effect on the Min River (Min-jiang 岷江). With great benefit and little destruction, it can be taken as a masterpiece of man-made construction that achieved

${ }^{2}$ See Fairbank (1978, 108-9). 
harmony between human beings and nature. However, this case cannot be reproduced because it depends on the unique natural conditions.

An example of maximization of change is the Zipingpu Water Conservation Project (Zipingpu-shui-ku 紫坪铺水库), which is suspected of having induced the 2008 Wenchuan (汶川) Earthquake. The Zipingpu Water Conservation Project, located several kilometers away from the Dujiangyan irrigation system, is a large construction project built in the twenty-first century with a characteristically huge dam and reservoir. Because the end of the reservoir is located at the center of the Wenchuan earthquake, it is likely that the earthquake was induced by the pressure from the reservoir.

\section{PRACTICAL WISDOM: BALANCE IN TENSION}

There is no possibility of thoroughly solving ecological problems; they can only be mitigated. Any radical approach, which always sounds rational theoretically, is not acceptable or even possible for dealing with ecological problems in practice. An ecosystem in its natural state is welcome by everybody, but no one can endure a completely natural life. The crux is to keep a balance between an ecosystem and human life. In order to achieve the balance, we need to pay close attention to three factors: population, GDP and capitalist system.

The control of the absolute quantity of population is the most important measure in solving the ecological problem. As to the control of population, the countries that have a high population growth rate need to reduce it, while those having low growth rate need not increase it. Whether to reduce or increase it, policies should be deliberate and moderate. In this sense, other countries should learn from the lesson of China's extreme policies, i.e., either opposing any birth control until the 1960s or coercing a one-child policy by the State Family Planning.

The globalization of population control is the only way to solve the ecological problem. In order to avoid the destruction of local and global ecosystems caused by the expansion of population in particular regions, it is necessary to enable the free flow of populations and to achieve a balance between the density of population and the global ecosystem. Thus, as regards distribution of population, nationalist consciousness should be weakened, while cosmopolitan consciousness should be strengthened.

In order to relieve the ecological problem, the focus is the minimization of the destruction resulted from GDP. Within the sphere of human capacity, it is necessary to maximize the rate of utilization of natural resources and minimize the quantity of destruction. The gross quantity of world GDP cannot keep growing indefinitely. The limitation with respect to both the growth rate and the amount of GDP must be controlled to protect worldwide ecological systems.

We must clarify the ecological limit of capitalism. Capitalism is probably the optimal mechanism for increasing GDP, but it is definitely not the best mechanism for ecological protection. 
Capitalism is presently the basic mode of producing GDP for human beings, and is also the main mode of ecosystem destruction. The value of GDP growth is to eliminate poverty and enhance the quality of people's lives. The capitalist way to eliminate poverty has shown that in order to increase poor people's income, you need to multiply the income of the rich. Thus, the quantity of increased GDP will always surpass the quantity required to eliminate poverty. The marginal effect of increasing income diminishes progressively for the improvement of the rich people's lives, but grows progressively for the ecological problem. The intensification of ecological problems will finally decrease the life quality of all human beings.

In this sense, Rawls's difference principle, which explicitly takes the advantage of the least favored as the precondition of an unequal distribution ${ }^{3}$ but, conversely, implicitly takes the multiplied advantage of the most favored as the precondition of the basic advantage of the least favored, may be socially just but ecologically unjust.

It is clear that the common ecological safety of humankind is more important than the institutional value of capitalism. Ecological safety is the limit that has been set for all human beings. Such a limitation cannot be broken for the purpose of increasing GDP.

In summary, history will not end in capitalism. Rather, the ecological Da-tong is more desirable. Da-tong (大同, the Great Unity) is a traditional Chinese notion referring to a Utopian vision of the world in which everyone and everything will be at peace, ${ }^{4}$ and the ecological Da-tong means a globalized human society with ecologically sustainable development. Certainly the ecological Da-tong is not a solution to ecological problems, but a regulative idea in Kantian sense ${ }^{5}$ for the solution.

\section{ACKNOWLEDGMENTS}

This article is an outcome of the project (13AZX003) of the National Foundation for Social Sciences, "A Study of the Linguistic Turn in Marx’s Practical Philosophy".

\section{REFERENCES}

Fairbank, John K. (1978), The Cambridge History of China, Volume 10, Late Ch'ing, 1800-1911, Part I (Cambridge: Cambridge University Press).

Kang You-wei (2007), Da-Tong (Great Unity), in Complete Works of Kang You-wei, vol. 2, ed. Yihua Jiang and Ronghua Zhang (Beijing: China Renmin University Press).

\footnotetext{
${ }^{3}$ See Rawls (1971, 302).

${ }^{4}$ See Kang You-wei (2007,184-188).

${ }^{5}$ About the concept of regulative, see Kant $(1933,450)$.
} 
Kant, Immanuel (1933), Critique of Pure Reason, trans. Norman Kemp Smith (London: The Macmillan Press).

Rawls, John (1971), A Theory of Justice (Cambridge: the Belknap Press of Harvard University Press). 